\title{
The role of ECG as a mortality predictor in COVID-19 patients treated in the intensive care unit
}

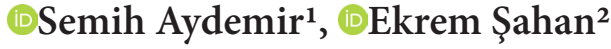 \\ ${ }^{1}$ Atatürk Pulmonary Disease and Thorax Surgery Training and Research Hospital, Department of Anesthesiology and Reanimation, Ankara, Turkey \\ ${ }^{2}$ Atatürk Pulmonary Disease and Thorax Surgery Training and Research Hospital, Department of Cardiology, Ankara, Turkey
}

Cite this article as: Aydemir S, Sahan E. The role of ECG as a mortality predictor in COVID-19 patients treated in the intensive care unit. J Health Sci Med 2021; 4(6): 892-896.

\begin{abstract}
Background: COVID-19 infection has reached serious morbidity and mortality rates all over the world for a short time. Many studies have investigated the relationship of COVID-19 disease with mortality and morbidity. In this study, we wanted to elucidate the relationship between rhythm character (sinus rhythm vs atrial fibrillation) and QTc and frontal plane QRS-T angle, which parameters are reflecting the depolarization-repolarization kinetics, and mortality, which were not emphasized enough in previous studies.

Material and Method: 259 patients admitted to the intensive care unit due to COVID-19 infection between 01.04.2020 and 01.12.2020 was included in the study. The demographic characteristics of the patients, clinical backgrounds, laboratory values at the time of admission to the intensive care unit, and 12 derivation ECG records were obtained from the patient files. Rhythm, PR distance, QRS duration and morphology, QT interval, T wave morphology, presence of atrioventricular (AV) block, QRS axis, presence of ventricular premature contraction, frontal plane QRS-T ( $(\mathrm{QRS}-\mathrm{T})$ ) angle degree were determined on 12 derivation ECG records. Patient groups were classified as "deceased patient" and "survivors" and the relationship of these parameters with survival was tried to be elucidated.

Results: the frequency of atrial fibrillation was significantly higher in the "deceased patient" group. For patients in sinus rhythm, there was no difference between the two groups in terms of PR distance and 1st degree AV block. Severe AV block was not observed in either group. There was no difference between the two groups in terms of QRS morphology, T wave inversion, and ventricular premature contractions. QRS duration, corrected QTc duration, and frotal plane QRS-T angle values were found to be statistically significantly higher in in the "deceased patient" group.

Conclusion: Atrial fibrillation, prolonged QTc duration and increased frontal plane QRS-T angle can be considered as mortality predictors in COVID-19 infection whose mortality rate is high all over the world.
\end{abstract}

Keywords: COVID-19, ECG, AF, QRS-T angle, mortality

\section{INTRODUCTION}

COVID-19 disease, caused by the severe acute respiratory syndrome Coronavirus 2 (SARS-Cov-2) virus, continues to affect the whole world for more than a year. The rate of spread of the infection is very high, as the number of infected patients increases, morbidity and mortality numbers also increase $(1,2)$. Pneumonia caused by the COVID-19 disease creates respiratory stress, and the need for non-invasive or invasive mechanical ventilation support may arise. With the treatment administered in the intensive care unit, clinical recovery occurs as well as mortality.

Electrocardiography (ECG) is one of the most frequently used diagnostic tests in clinical practice. Many studies have shown the prognostic significance of ECG findings in many diseases, especially in cardiovascular system diseases. Information on COVID-19 infection is newly accumulating, and information on the clinical course and mortality of COVID-19 is emerging with the studies. In the early stages of Covid 19 infection, ECG findings especially QTc value - were used to determine treatment options and side effects of treatment (3). In addition, studies related to Covid 19 mortality and ECG findings are also published. In addition, studies related to Covid 19 mortality and ECG findings have begun to be published. Our aim in this study is to reveal the relationship between in-hospital mortality and data and parameters to be obtained from 12-lead ECGs of patients who have been followed up in intensive care with COVID-19 infection. 


\section{MATERIAL AND METHOD}

259 patients admitted to the intensive care unit due to COVID-19 infection between 01.04.2020 and 01.12.2020 were included in the study. The demographic characteristics of the patients, clinical backgrounds, laboratory values at the time of admission to the intensive care unit, and 12 derivation ECG records were obtained from the patient files. Rhythm, PR distance, QRS duration and morphology, QT interval, T wave morphology, presence of atriventricular (AV) block, QRS axis, presence of ventricular premature contraction, frontal plane $\mathrm{QRS}-\mathrm{T}(\mathrm{f}(\mathrm{QRS}-\mathrm{T}))$ angle degree were determined on 12 derivation ECG records. Patient groups were classified as "deceased patient" and "survivors" and the relationship of these parameters with survival was tried to be elucidated. This retrospective study was carried out with the permission of Keçiören Trainig and Research Hospital Clinical Researchs Ethics Committee (Date: 22.12.2020, Decision No: 15/2206). All procedures were carried out in accordance with the ethical rules and the principles of the Declaration of Helsinki.

12 leads ECG recordings were performed at a speed of $25 \mathrm{~mm} / \mathrm{sec}$ and with a height of $10 \mathrm{~mm} / \mathrm{mV}$. In 12 derivations ECG, recordings with irregular R-R distance without $\mathrm{P}$ waves were accepted as atrial fibrillation (AF). Recordings longer than 120 milliseconds were defined as Right Bundle Branch Block or Left Bundle Branch Block according to their morphology. Other wide QRS morphology that does not fit this classification was collected under the interventricular conduction defect (IVCD). The corrected QT (QTc) distance is calculated according to the Bazett formula. All ECG records had automatically reported QRS axis and T axis data. The angle $f(Q R S-T)$ was calculated from these angles as the distance between the QRS axis and the T axis.

\section{Statistical Analysis}

SPSS for Windows version 23.0 (SPSS Inc., IL, USA) was used for statistical analysis. Continuous variables were expressed as means \pm standard deviations and categorical variables were expressed as percentages. Continuous data were compared using Student's t test. Categorical data were compared using the chi-square test. With ch square test, Pearson's correlation coefficient was used for correlation analysis. A value of $\mathrm{p}<0.05$ was considered statistically significant.

\section{RESULTS}

When the patient groups were compared, the mean age was higher in the "deceased patient" group $(71.15 \pm 10.75 \mathrm{vs.}$ $63.09 \pm 12.69 ; \mathrm{p}<0.001)$. When co-morbidities were taken into account, heart failure and history of cerebrovascular events were statistically significantly higher in the "deceased patient" group, while there was no statistically significant difference in terms of hypertension, coronary artery disease, diabetes mellitus, malignancy, chronic obstructive pulmonary disease and gender (Table 1).

When ECG parameters were examined, the frequency of atrial fibrillation was significantly higher in the "deceased patient" group. For patients in sinus rhythm, there was no difference between the two groups in terms of PR distance and $1^{\text {st }}$ degree AV block. Severe AV block was not observed in either group. There was no difference between the two groups in terms of QRS morphology, T wave inversion, and ventricular premature contractions. QRS duration, corrected QTc duration, and frotal plane QRS-T angle values were found to be statistically significantly higher in in the "deceased patient" group (Table 2).

\begin{tabular}{|c|c|c|c|}
\hline & $\begin{array}{c}\text { Died } \\
n=101\end{array}$ & $\begin{array}{c}\text { Survived } \\
\mathrm{n}=158\end{array}$ & $\begin{array}{c}\mathbf{P} \\
\text { value }\end{array}$ \\
\hline Age & $71.15 \pm 10.75$ & $63.09 \pm 12.69$ & $<0.001$ \\
\hline Gender & & & 0.171 \\
\hline Female & $33(32.7 \%)$ & $65(41.1 \%)$ & \\
\hline Male & $68(67.3 \%)$ & $93(58.9 \%)$ & \\
\hline Hypertension & $44(43.6 \%)$ & $81(51.3 \%)$ & 0.226 \\
\hline Diabetes mellitus & $23(22.8 \%)$ & $38(24.1 \%)$ & 0.813 \\
\hline $\begin{array}{l}\text { Coronary artery } \\
\text { disease }\end{array}$ & $21(20.8 \%)$ & $28(17.7 \%)$ & 0.538 \\
\hline Heart failure & $9(8.9 \%)$ & $5(3.2 \%)$ & 0.046 \\
\hline $\begin{array}{l}\text { Chronic obstructive } \\
\text { pulmonary disease }\end{array}$ & $16(15.8 \%)$ & $21(13.3 \%)$ & 0.567 \\
\hline Malignancy & $6(5.9 \%)$ & $12(7.6 \%)$ & 0.610 \\
\hline $\begin{array}{l}\text { Cerebrovascular } \\
\text { event }\end{array}$ & $8(7.9 \%)$ & $4(2.5 \%)$ & 0.044 \\
\hline Glucose $(\mathrm{mg} / \mathrm{dL})$ & $189.55 \pm 96.22$ & $175.69 \pm 99.48$ & 0.270 \\
\hline Creatinine (mg/dL) & $1.22 \pm 0.44$ & $1.01 \pm 0.31$ & $<0.001$ \\
\hline $\mathrm{GFR}(\mathrm{mL} / \mathrm{min})$ & $61.51 \pm 23.11$ & $80.53 \pm 78.19$ & 0.018 \\
\hline Albumine (mg/dL) & $3.05 \pm 0.46$ & $3.36 \pm 0.61$ & $<0.001$ \\
\hline AST (IU/L) & $69.89 \pm 93.02$ & $43.57 \pm 39.29$ & 0.002 \\
\hline ALT (IU/L) & $51.61 \pm 77.61$ & $37.54 \pm 42.01$ & 0.061 \\
\hline GGT (IU/L) & $69.44 \pm 83.69$ & $64.10 \pm 83.19$ & 0.616 \\
\hline LDH (IU/L) & $639.64 \pm 428.56$ & $391.51 \pm 185.71$ & $<0.001$ \\
\hline CRP (mg/dL) & $141.93 \pm 99.01$ & $109.52 \pm 99.40$ & 0.011 \\
\hline Ferritin $(\mathrm{ng} / \mathrm{mL})$ & $791.42 \pm 522.57$ & $465.60 \pm 459.42$ & $<0.001$ \\
\hline $\mathrm{D}$-dimer $(\mathrm{mg} / \mathrm{L})$ & $6.85 \pm 15.19$ & $2.93 \pm 9.33$ & 0.012 \\
\hline Troponin (ng/L) & $532.45 \pm 2459.57$ & $33.79 \pm 177.63$ & 0.012 \\
\hline Lactate $(\mathrm{mmol} / \mathrm{L})$ & $3.43 \pm 2.50$ & $1.21 \pm 0.81$ & $<0.001$ \\
\hline Sat $\mathrm{O}_{2}(\%)$ & $74.07 \pm 8.78$ & $85.79 \pm 7.82$ & $<0.001$ \\
\hline $\mathrm{WBC}\left(\times 10^{3} / \mu \mathrm{L}\right)$ & $12.4899 \pm 6.2614$ & $8652.6 \pm 3866.1$ & $<0.001$ \\
\hline $\begin{array}{l}\text { Neutrophile } \\
\left(\times 10^{3} / \mu \mathrm{L}\right)\end{array}$ & $10.8151 \pm 5.8133$ & $7008.4 \pm 3917.7$ & $<0.001$ \\
\hline $\begin{array}{l}\text { Lymphocyte } \\
\left(\times 10^{3} / \mu \mathrm{L}\right)\end{array}$ & $992.2 \pm 1671.9$ & $1139.1 \pm 616.7$ & 0.317 \\
\hline Platelet & $241144 \pm 113290$ & $257284 \pm 98665$ & 0.227 \\
\hline $\operatorname{Hgb}(\mathrm{g} / \mathrm{dL})$ & $13.37 \pm 2.18$ & $13.34 \pm 1.65$ & 0.903 \\
\hline
\end{tabular}




\begin{tabular}{|lccc|}
\hline \multicolumn{4}{|c|}{ Table 2. ECG findings and characteristics of the study patients } \\
\hline & $\begin{array}{c}\text { Died } \\
\mathbf{n}=101\end{array}$ & $\begin{array}{c}\text { Survived } \\
\mathbf{n}=158\end{array}$ & P value \\
\hline Heart rate (b.p.m) & $102.68 \pm 25.04$ & $90.77 \pm 19.14$ & $<0.001$ \\
Rythm & & & $<0.001$ \\
$\quad$ Sinus Rythm & $83(82.2 \%)$ & $157(99.4 \%)$ & \\
Atrial Fibrillation & $18(17.8 \%)$ & $1(0.6 \%)$ & \\
PR interval (msec) & $152.70 \pm 24.10$ & $154.31 \pm 28.48$ & 0.796 \\
First degree AV block & $3(3.6 \%)$ & $8(5.1 \%)$ & 0.602 \\
QRS (msec) & $95.77 \pm 16.53$ & $92.04 \pm 13.83$ & 0.051 \\
QRS morphology & $77(76.2 \%)$ & $129(81.6 \%)$ & 0.489 \\
$\quad$ Normal & $15(14.9 \%)$ & $22(13.9 \%)$ & \\
IVCD & $6(5.9 \%)$ & $4(2.5 \%)$ & \\
\hline LBBB & $3(3.0 \%)$ & $3(1.9 \%)$ & \\
$\begin{array}{l}\text { RBBB } \\
\text { Ventricular premature } \\
\text { contraction }\end{array}$ & $14(13.9 \%)$ & $16(10.1 \%)$ & 0.360 \\
$\begin{array}{l}\text { Corrected QT (msec) } \\
\text { T wave inversion }\end{array}$ & $426.75 \pm 35.50$ & $416.97 \pm 25.66$ & 0.011 \\
$\begin{array}{l}\text { Abnormal QRS axis } \\
\text { Frontal Plane QRS-T } \\
\text { angle (0) }\end{array}$ & $14(13.9 \%)$ & $11(7.0 \%)$ & 0.067 \\
\hline $\begin{array}{l}\text { IVCD: interventricular conduction disease, LBBB: left bundle brunch block, RBBB: } \\
\text { right bundle brunch block }\end{array}$ & $64.96 \pm 52.69$ & $37.90 \pm 34.43$ & $<0.001$ \\
\hline
\end{tabular}

As an acute phase reactant, albumin levels were significantly lower in the "deceased patient" group, and ferritin and C-reactive protein (CRP) levels were significantly higher in the "deceased patient" group. There was a statistically significant difference between the two groups in terms of creatinine, glomerule filtration rate (GFR), aspartate transaminase (AST), lactic acid dehydrogenase (LDH), troponin, d-dimer, lactate and $\mathrm{Sat}_{2}$, white blood count (WBC), neutrophil count (Table 1).

\section{DISCUSSION}

COVID-19 infection rapidly affected the whole world, reaching high mortality rates with the increase in the number of infected patients and the respiratory stress it caused. The fact that the infection is caused by a newly emerging virus limits the diagnosis and treatment options, and as the knowledge about the disease increases, knowledge about the clinical course and causes of mortality increases.

The 12 derivation ECG is one of the most frequently used tests in emergency services, outpatient clinic visits, inpatient wards and intensive care units. Until today, the relationship between the clinical course and mortality of many diseases, especially cardiovascular diseases, and ECG findings has been revealed. Some studies on COVID-19 disease and ECG have been published, and the number of studies demonstrating its relationship with mortality is small, and different parameters were used in each study (6-10). In this study, we wanted to reveal the relationship between ECG parameters and COVID -19 and emphasize the importance of rhythm character and the frontal plane QRS-t angle, which reflects especially the depolarization-repolarization state.

It is emphasized in the updated atrial fibrillation guidelines that the mortality due to all causes is 1.5-3.5 times higher in patients diagnosed with atrial fibrillation, and the presence of AF in addition to those with cardiovascular disease increases mortality and morbidity (11). Among the 259 patients included in the study, 19 patients had a diagnosis of atrial fibrillation. The clinical course of 18 of these patients ended with mortality. In studies conducted with COVID-19 infection, the relationship between AF and mortality has not been emphasized enough, and considering the results of this study, COVID-19 patients with AF may be considered to be at higher risk for mortality.

QT distance is one of the reflections of the ventricular depolarization and repolarization process on the ECG. The relationship between corrected QT (QTc) duration and ventricular arrhythmias and mortality has been demonstrated $(12,13)$. With prolonged QTc, the frequency of ventricular arrhythmias and mortality rate increases especially in cardiovascular diseases. Prolonged QTc duration has been reported to be associated with prognosis in COVID-19 infection $(14,15)$. In our study, the QTc duration was found to be significantly longer in the "deceased patient" group. Considering the results of the study, the prolonged QTc duration may be considered as a mortality predictor in patients diagnosed with COVID-19. In addition, the number of patients with an abnormal QRS axis other than 0-90 degrees is higher in the "deceased patient" group. There was no significant difference between the two groups in terms of the frequency of ventricular premature contraction (VPC). It was concluded that the frequency of VPC does not have a clear effect on mortality in the study population. There was no significant difference between the two groups in terms of PR duration and the frequency of first degree atrioventricular block in the study population. 2nd and 3rd degree atrioventricular block, which is associated with cardiovascular system morbidity and mortality, was not observed in the rhythm records of both groups.

The frontal plane QRS-T angle $\mathrm{f}(\mathrm{QRS}-\mathrm{T})$, is another ECG parameter that reflects the ventricular deoplarizationrepolarization process (16). In previous studies, increased $\mathrm{f}$ (QRS-T) angle was found to be associated with mortality in the general population and cardiovascular disease (17-19). In our study, higher $\mathrm{f}(\mathrm{QRS}-\mathrm{T})$ angle values were observed in the "deceased patient" group compared to the surviving patients. Increased $f(Q R S-T)$ angle was thought to be associated with an increased risk of mortality in patients with a diagnosis of COVID- 19 . 
Considering the demographic characteristics and laboratory results of the study population, there was a higher mean age in the deceased patient group. In previous studies, it was stated that mortality in covid 19 patients increased with increasing age $(20,21)$. Heart failure and history of cerebrovascular disease were statistically significantly higher in the deceased patient group. However, there was no significant difference between the two groups in terms of diseases with high mortality rates such as hypertension, diabetes mellitus, coronary artery disease, chronic obstructive pulmonary disease, malignancy and gender. In addition, as acute phase reactants, low albumin, high CRP and ferritin were statistically significant in the deceased patient group, same as results of previous studies $(22,23)$. In our study, as in previous studies, troponin and d-dimer levels were higher in the patient group who died, and their relationship with mortality was also revealed in this study $(24,25)$.

\section{CONCLUSION}

Atrial fibrillation, prolonged QTc duration and increased frontal plane QRS-T angle can be considered as mortality predictors in COVID-19 infection, whose mortality rate is high all over the world. We think that patients with these parameters can be evaluated as high-risk and closely monitored from the time of diagnosis, and positive effects on mortality rates can be achieved.

\section{ETHICAL DECLARATIONS}

Ethics Committee Approval: The study was carried out with the permission of Keçiören Trainig and Research Hospital Clinical Researchs Ethics Committee (Date: 22.12.2020, Decision No: 15/2206).

Informed Consent: Because the study was designed retrospectively, no written informed consent form was obtained from patients.

Referee Evaluation Process: Externally peer-reviewed.

Conflict of Interest Statement: The authors have no conflicts of interest to declare.

Financial Disclosure: The authors declared that this study has received no financial support.

Author Contributions: All of the authors declare that they have all participated in the design, execution, and analysis of the paper, and that they have approved the final version.

\section{REFERENCES}

1. Hassan M, Zalkifal M, Wahab A, et al. Novel Coronavirus: A Review from Origin to Current Status of Therapeutic Strategies. Crit Rev Eukaryot Gene Expr 2021; 31: 21-34.
2. Alves VP, Casemiro FG, Araujo BG, et al. Factors associated with mortality among elderly people in the COVID-19 pandemic (SARS-CoV-2): a systematic review and meta-analysis. Int J Environ Res Public Health 2021; 18: 8008.

3. Ding J, Liu W, Guan H, et al. Corrected QT interval in hospitalized patients with coronavirus disease 2019: focus on drugs therapy. Medicine (Baltimore) 2021; 100: e26538.

4. Bertini M, D'Aniello E, Cereda A, et al. The Combination of chest computed tomography and standard electrocardiogram provides prognostic information and pathophysiological insights in COVID-19 pneumonia. J Clin Med 2021; 10: 3031.

5. Haji Aghajani M, Toloui A, Aghamohammadi $M$, et al. Electrocardiographic findings and in-hospital mortality of COVID-19 patients; a retrospective cohort study. Arch Acad Emerg Med 2021; 9: e45.

6. McCullough SA, Goyal P, Krishnan U, Choi JJ, Safford MM, Okin PM. Electrocardiographic findings in coronavirus disease-19: insights on mortality and underlying myocardial processes. J Card Fail 2020; 26: 626-632.

7. Lanza GA,De Vita A, Ravenna SE, et al. Electrocardiographic findings at presentation and clinical outcome in patients with SARS-CoV-2 infection. Europace 2021; 23: 123-9.

8. Elias P, Poterucha TJ, Jain SS, et al. The prognostic value of electrocardiogram at presentation to emergency department in patients with COVID-19. Mayo Clin Proc 2020; 95: 2099-109.

9. Wang Y, Chen L, Wang J, et al. Electrocardiogram analysis of patients with different types of COVID-19. Ann Noninvasive Electrocardiol 2020; 25: e12806.

10. Li Y, Liu T, Tse G, et al. Electrocardiograhic characteristics in patients with coronavirus infection: A single-center observational study. Ann Noninvasive Electrocardiol 2020; 25: e12805.

11.Hindricks G, Potpara T, Dagres N, et al 2020 ESC Guidelines for the diagnosis and management of atrial fibrillation developed in collaboration with the European Association of Cardio-Thoracic Surgery (EACTS). Eur Heart J 2020; 42: 373-98.

12. Moss AJ. Measurement of the QT interval and the risk associated with QTc interval prolongation: a review. Am J Cardiol 1993; 72: 23B-25B.

13. Hondeghem LM. QT prolongation is an unreliable predictor of ventricular arrhythmia. Heart Rhythm 2008; 5: 1210-2.

14. Akhtar Z, Gallagher MM, Yap YG, et al. Prolonged QT predicts prognosis in COVID-19.Pacing Clin Electrophysiol 2021; 44: 875-82.

15. Changal K, Paternite D, Mack S, et al. Coronavirus disease 2019 (COVID-19) and QTc prolongation. BMC Cardiovasc Disord 2021; $21: 158$.

16. Oehler A, Feldman T, Henrikson CA, Tereshchenko LG.QRS-T angle: a review. Ann Noninvasive Electrocardiol 2014; 19: 534-42.

17. Gotsman I,Keren A, Hellman Y, Banker J, Lotan C, Zwas DR. Usefulness of electrocardiographic frontal QRS-T angle to predict increased morbidity and mortality in patients with chronic heart failure. Am J Cardiol 2013; 111: 1452-9.

18. Aro AL, Huikuri HV, Tikkanen JT, et al. QRS-T angle as a predictor of sudden cardiac death in a middle-aged general population. Europace 2012; 14: 872-6.

19. Lown MT, Munyombwe T, Harrison W, et al. Association of frontal QRS-T angle--age risk score on admission electrocardiogram with mortality in patients admitted with an acute coronary syndrome. Am J Cardiol 2012; 109: 307-13.

20.Liu Y, Mao B, Liang S, et al. Association between age and clinical characteristics and outcomes of COVID-19. Eur Respir J 2020; 55: 5 .

21.Moraga P, Ketcheson DI, Ombao HC, Duarte CM. Assessing the age- and gender-dependence of the severity and case fatality rates of COVID-19 disease in Spain.Wellcome Open Res 2020; 5: 117. 
22.Jain AC, Kansal S, Sardana R, Bali RK, Kar S, Chawla R. A retrospective observational study to determine the early predictors of in-hospital mortality at admission with COVID-19. Indian J Crit Care Med 2020; 24: 1174-9.

23. Deng F, Zhang L, Lyu L, et al. Increased levels of ferritin on admission predicts intensive care unit mortality in patients with COVID-19. Med Clin (Barc) 2021; 156: 324-31.

24.Zhang L, Yan X, Fan Q, et al. D-dimer levels on admission to predict in-hospital mortality in patients with COVID-19. J Thromb Haemost 2020; 18: 1324-9.

25.Lippi G, Lavie CJ, Sanchis-Gomar F. Cardiac troponin I in patients with coronavirus disease 2019 (COVID-19): evidence from a meta-analysis. Prog Cardiovasc Dis 2020; 63: 390-1. 